\title{
SCIDoc

\section{Skin Score Predictive of Mortality and Morbidity in Scleroderma}

Ehmouda Zaid $\mathrm{F}^{1^{*}}$, Zidan $\mathrm{T}^{2}$

${ }^{1}$ Association Professor, Department of Rheumatology in Faculty of Medicine, Benghazi University, Libya.

${ }^{2}$ Department of Rheumatology, Benghazi University, Libya.

\section{Abstract}

The severe skin disease in scleroderma can reflect increased mortality and frequency of internal organ complications, The purpose of this study was determined relationship between skin score with morbidity and mortality in patients with scleroderma.

Results: Forty two patients diagnosed with scleroderma were included in the study, The patients were divided in to two groups according to criteria of diagnosis (78.6\%) were Diffuse Systemic Sclerosis (DSS) and (21.4\%) were Limited Systemic Sclerosis (LSS), the cutaneous manifestation more in Diffuse Systemic Sclerosis( DSS) than Limited Systemic Sclerosis (LSS), during follow up the mortality was $(14.2 \%)$ and morbidity $(35.7 \%)$ common morbidity $(33.3 \%)$ were interstitial lung disease, followed $(28.6 \%)$ were pulmonary hypertension then $(4.8 \%)$ were pulmonary hypertension $(\mathrm{PAH})$ with $\mathrm{C}$ or pulmonale then $(7.1 \%)$ were Hypertension and hemodialysis. high skin score $>35$ association with mortality $\mathrm{P}(0.002)$ And renal disease $\mathrm{P}(0.0001)$, Skin score (20-30) association with interstitial lung disease (ILD) $\mathrm{p}(0.005)$ and skin score (12-26) association with anti-topo Isomerase antibodies $\mathrm{P}(0.001)$.

Conclusion: Cutaneous manifestations are more in diffuse systemic sclerosis than limited systemic sclerosis. The frequency of internal organs involvement is more in diffuse systemic sclerosis than limited systemic sclerosis, high skin score was predicted mortality and internal organ complication like renal crisis and interstitial lung disease.

Keywords: Diffuse Systemic Sclerosis; Limited Systemic Sclerosis; Mortality; Skin Score.

\section{Introduction}

The word scleroderma literally means "hard skin" and describes the most dramatic clinical feature of the disease [1], The amount of skin thickening can be quantified by performing a MRSS (Modified Rodnan Skin Score) in which the skin is pinched between the examiner's thumbs in 17 specified areas of the patient's body, scoring the thickness of the skin from 0 (normal) to 3 (very thick). The maximum skin score can reflect disease severity and mortality $[3,5]$.

Scleroderma are typically classified based on the amount and location of skin involvement into; Limited systemic sclerosis( LSS) and Diffuse systemic sclerosis (DSS) [2].

The Limited systemic sclerosis have skin sclerosis restricted to the hands and, to a lesser extent, to the face and neck and also have prominent vascular manifestations and may suffer from the CREST syndrome (Calcinosis cutis, $\mathrm{R}$ aynaud phenomenon, $\mathrm{E}$ sophageal.

dysmotility, Sclerodactyly, and Telangiectasia). While Diffuse systemic sclerosis have extensive skin sclerosis and are at a greater risk for the development of significant renal, lung, and cardiac disease [2].

The purpose of this study was determined relationship between skin score and morbidity and mortality in patients with scleroderma.

\section{Patient and Method}

This study was carried out at the Rheumatology department in Benghazi University, Follow up study patients were diagnosed

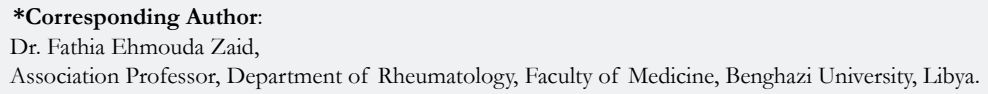

Copyright: Ehmouda Zaid $\mathbf{F}^{\circ}$ 2019. This is an open-access article distributed under the terms of the Creative Commons Attribution License, which permits unrestricted use, distribution and reproduction in any medium, provided the original author and source are credited. 
scleroderma according American College of Rheumatology (ACR) from recorded rheumatology clinic at $7^{\text {th }}$ October-Hospital, these patients were assessment clinically and laboratory test every 3 months in period between 2010 and 2019.

The assessment of skin involvement was quantified by using the (MRSS) Modified Rodnan Skin Score and assessment of organ involvement by history, physical examination and especial test like Echocardiography or CT scan chest and Blood test, The correlation between mean skin score and morbidity or mortality or specific organ involvement were calculated using unpaired T-test. $\mathrm{P}$ values less 0.05 were significant.

\section{Result}

Forty two patients diagnosed with scleroderma were included in the study .Patient's clinical characteristics are shown below (Table $1)$. The age of the study patients ranged from(20-62 years), $M=$ (44 \pm 11 years), were female $(92.9 \%)$ and male $(7.1 \%)$, Duration of disease range from (1-25 years), $\mathrm{M}=(11 \pm 7 \mathrm{y})$, The patients were divided in to two groups according to criteria of diagnosis (78.6\%) were Diffuse Systemic Sclerosis (DSS) and (21.4\%) were Limited Systemic Sclerosis (LSS), Serology test was done antinuclear Antibody ANA (95.2\%) positive Anti Centromere Antibody ACA $(21.4 \%)$ positive and Anti-Topoisomerase antibody (74\%) positive, skin score range from (10-45) $\mathrm{M}=(22 \pm 11)$, during follow up the mortality was (14.2\%) and morbidity (35.7\%), common morbidity was interstitial lung disease, followed pulmonary hypertension then pulmonary hypertension (PAH) with Cor pulmonale then Hypertension and hemodialysis. According cutaneous manifestation in Figure (1) we found skin thickness (82\%) in DSS, while (55\%) in LSS, Raynaud phenomenon (88\%) in DSS, while $(78 \%)$ in LSS, Digital ulcer $(55 \%)$ in DSS, while $(33 \%)$ in LSS, Telangiectasia $(30.3 \%)$ in DSS, while $(22 \%)$ in LSS, Pigmentation $(61 \%)$ in DSS, while $(33.3 \%)$ in LSS, Depigmentation $(42.4 \%)$ in DSS, while $(22 \%)$ in LSS, Calcinosis $(6.10 \%)$ while $(11 \%)$ in LSS and Vasculitis $(9.10 \%)$ in DSS. According organ involvement in Figure (2) the musculoskeletal (MSK) (76\%) in DSS while $(56 \%)$ in LSS, interstitial lung disease (ILD) (42\%) in DSS, pulmonary hypertension (PAH) $(27 \%)$ in DSS while $(33 \%)$ in LSS, gastrointestinal tract (GIT) (61\%) in DSS while (78\%) in LSS and Renal disease (15\%) in DSS. the relationship between skin score and mortality or morbidity or organ involved are shown below (Table 2) The mean skin score of patients were died (37.7) with P (0.002), The mean skin score of patients with morbidity (25.9) with $\mathrm{p}(0.279)$, mean skin score of patients with $\operatorname{ILD}(30.6)$ with $\mathrm{P}(0.005)$,the mean skin score of patients with MSK (23.2) with $\mathrm{p}(0.789)$, the mean skin score of patients with renal disease ( 38) with $\mathrm{p}(0.0001)$, the mean skin score of patients with $\mathrm{PAH}(20)$ with $\mathrm{P}(0.556)$, the mean skin score of patients with gastrointestinal tract (GIT) (26) with P (0.556), The mean skin score patients with positive topo isomerse antibody (26.1) with $\mathrm{p}(0.001)$.

\section{Discussion}

Scleroderma is multi-system disease characterized by skin sclerosis and visceral disease One-third of patients with Scleroderma have the more Diffuse Systemic Sclerosis form of the disease [9]. In our study observed Diffuse Systemic Sclerosis (DSS) were more than Limited Systemic Sclerosis (LSS).

Skin involvement in the scleroderma is characterized by variable sclerosis or thickening of the skin and edematous swelling and erythema of the skin in the early stages [1] clinical manifestation of vascular dysfunction of scleroderma is Raynaud phenomenon or small dilated blood vessels (capillary telangiectasia) and digital ulcers with or without calcium deposits (calcinosis)( in our study the cutaneous manifestation more in Diffuse Systemic Sclerosis than Limited Systemic Sclerosis while vascular manifestation near to be same in both Diffuse Systemic Sclerosis and Limited Systemic Sclerosis, the skin thickness is more in Diffuse Systemic Sclerosis than Limited Systemic Sclerosis, Raynaud phenomenon and Telangiectasia are near same in both Diffuse Systemic Sclerosis and Limited Systemic Sclerosis while Digital ulcer is slight higher in Diffuse Systemic Sclerosis and Calcinosis is slight higher in Limited Systemic Sclerosis [6,16].

Figure 1. Skin involved in Scleroderm.

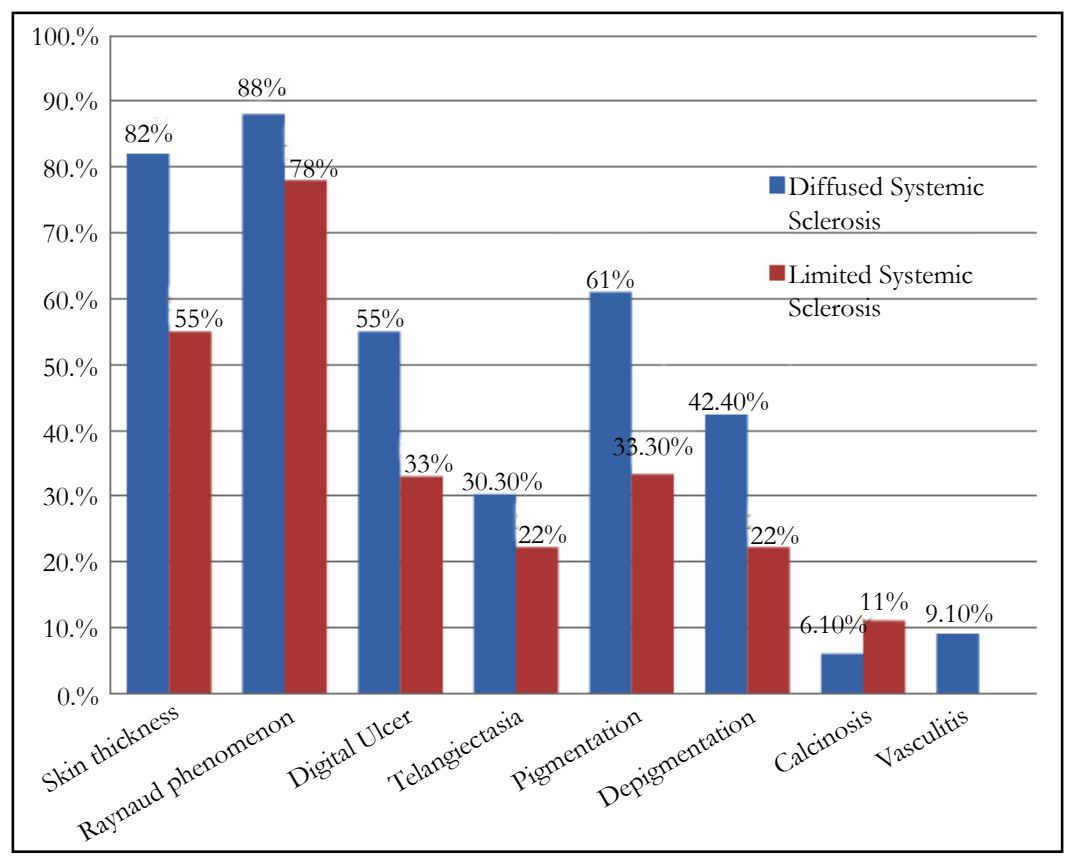


Figure 2. Organ Involvement Of Systemic Sclerosis.

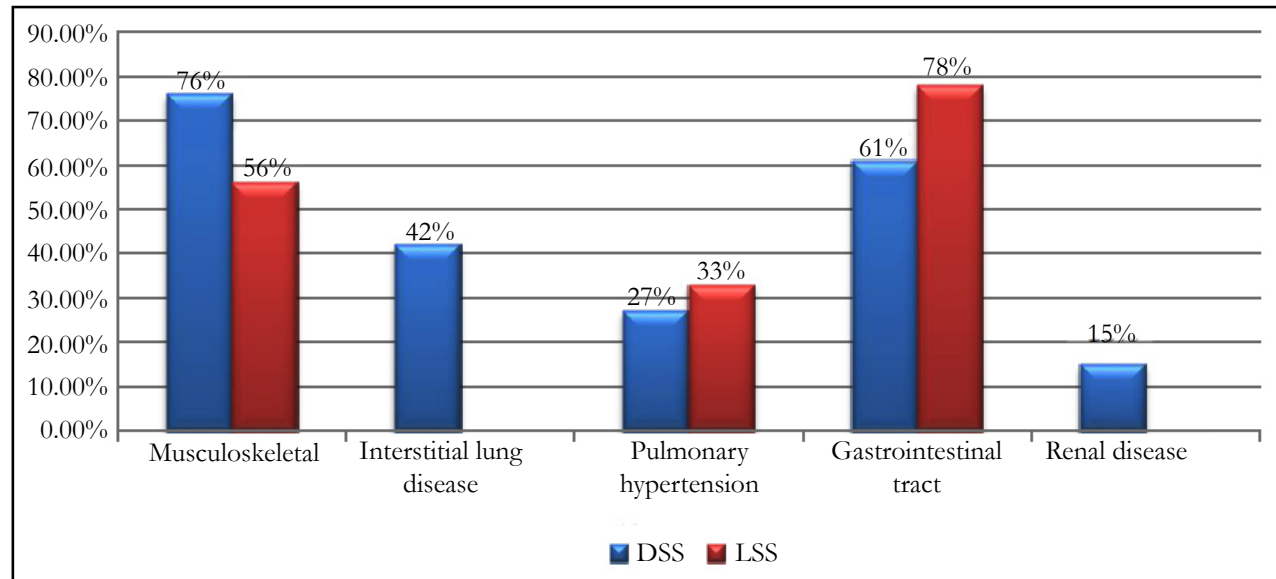

Table 1. Clinical Characteristics of patients with scleroderma.

\begin{tabular}{|c|c|}
\hline Age & $\begin{array}{c}25-62 \text { years } \\
M=(44 \pm 11 Y)\end{array}$ \\
\hline Sex & $\begin{array}{c}39 \text { female }(92.9 \%) \\
3 \text { male }((7.1 \%)\end{array}$ \\
\hline Duration disease & $\begin{array}{c}1-25 \text { year } \\
M=[11 \pm 7 y]\end{array}$ \\
\hline $\begin{array}{c}\text { Diffuse systemic sclerosis } \\
\text { DSS }\end{array}$ & $33(78.6)$ \\
\hline Limited systemic sclerosis LSS & $9(21.4 \%)$ \\
\hline $\begin{array}{l}\text { Serology antinuclearAntibody } \\
\text { ANA }\end{array}$ & $40(95.2 \%)$ \\
\hline $\begin{array}{l}\text { Anti Centromere Antibody } \\
\text { ACA }\end{array}$ & $9(21.4 \%)$ \\
\hline $\begin{array}{l}\text { Anti-Topoisomerase } \\
\text { antibody }\end{array}$ & $31(74 \%)$ \\
\hline Skin Score & $10-45 \mathrm{M}=(22 \pm 11)$ \\
\hline Mortality & $6(14.2 \%)$ \\
\hline Morbidity & $15(35.7 \%)$ \\
\hline $\begin{array}{l}\text { Interstitial Lung Disease } \\
\text { (ILD) } \\
\end{array}$ & $14(33.3 \%)$ \\
\hline $\begin{array}{c}\text { Pulmonary Hypertension } \\
\text { (PAH) }\end{array}$ & $12(28.6 \%)$ \\
\hline $\begin{array}{l}\text { Pulmonary Hypertension } \\
\text { (PAH) With Corpulmonale }\end{array}$ & $2(4.8 \%)$ \\
\hline Hypertension & $3(7.1 \%)$ \\
\hline Hemodialysis & $3(7.1 \%)$ \\
\hline $\begin{array}{l}\text { Sever Vasculitis With } \\
\text { Amputation Limb }\end{array}$ & $1(2.4 \%)$ \\
\hline
\end{tabular}

According organ involvement is more in Diffuse Systemic Sclerosis than Limited Systemic Sclerosis, the commonest musculoskeletal (MSK) and gastrointestinal tract (GIT) then interstitial lung disease (ILD) and Renal disease while pulmonary hypertension is more in Limited Systemic Sclerosis than Diffuse Systemic Sclerosis similarly in previous studies $[7,8,10]$.

The frequency of internal organs involvement, particularly the lungs and kidneys in Diffuse Systemic Sclerosis, which depend- ently on extent skin sclerosis and important prognostic factor. The gastrointestinal tract, although most frequently affected, is less life threatening. Pulmonary hypertension occurs more frequently in Limited Systemic Sclerosis which independently on extent skin sclerosis [10].

Co morbidity is more in Diffuse Systemic Sclerosis, Skin score (22-26) association with Co morbidity and common morbidity was interstitial lung disease, followed pulmonary hypertension then pulmonary hypertension (PAH) with Cor pulmonale then 
Table 2. Relationship between skin score and mortality, morbidity, organ involved.

\begin{tabular}{|l|c|c|}
\hline & Mean of skin score & P/ Value \\
\hline 1) Mortality & & 0.002 \\
\hline die & 37.7 & \\
\hline surviving & 21.1 & \\
\hline 2) Morbidity & & 0.279 \\
\hline with morbidity & 25.9 & \\
\hline without morbidity & 21.7 & \\
\hline 3) Interstitial lung disease( ILD) & & 0.005 \\
\hline with ILD & 30.6 & \\
\hline Without ILD & 19.9 & \\
\hline 4) Musculoskeletal (MSK) & & 0.789 \\
\hline With MSK & 23.2 & \\
\hline Without MSK & 21.8 & \\
\hline 5) Renal disease & & 0.000 \\
\hline With renal disease & 38 & \\
\hline Without renal disease & 20.5 & \\
\hline 6) Pulmonary hypertension (PAH) & & 0.556 \\
\hline With PAH & 20 & \\
\hline Without PAH & 23.3 & \\
\hline 7) Gastrointestinal tract (GIT) & & \\
\hline With GIT & 26.6 & \\
\hline Without GIT & & \\
\hline 8) AntiTopoisomerase antibody & & \\
\hline Postive & & \\
\hline Negative & & \\
\hline
\end{tabular}

Hypertension and hemodialysis [4, 12].

The extent of skin sclerosis has been considered an important prognostic factor (4) ,the skin score $>35$ increase mortality in scleroderma [11] and improvement in the skin score of at least $25 \%$ between baseline and the 2-year follow-up assessment had a 5 -year survival of $90 \%[14,15]$.

Several studies $[11,13,16,17]$ demonstrate that outcome of scleroderma is associated with baseline skin score and skin score associates with mortality and immunological were similarly in our study.

High skin score $>35$ increase mortality $\mathrm{P}(0.002)$ and frequency of internal organ complications like renal disease $\mathrm{P}(0.0001)$ and Skin score (20-30) association with ILD $\mathrm{p}(0.005)$, presence of antitopo I antibodies was associated with skin score (12-26) $\mathrm{P}(0.001)$.

\section{Conclusion}

Cutaneous manifestations are more in diffuse systemic sclerosis than limited systemic sclerosis.

The frequency of internal organs involvement is more in diffuse systemic sclerosis than limited systemic sclerosis.

The skin score cannot be used as index for organ-based involvement and powerful predictor of mortality and renal crisis.

\section{Recommendations}

Skin score should be evaluated annually in patients with systemic sclerosis in order to start appropriate treatment as early as possible to prevent mortality and morbidity in patients with high skin score.

\section{References}

[1]. Kowal-Bielecka O, Bielecki M, Kowal K. Recent advances in the diagnosis and treatment of systemic sclerosis. Pol Arch Med Wewn. 2013; 123:51-8. PMID: 23344666.

[2]. LeRoy EC, Black C, Fleischmajer R, JablonskaS, Krieg T, Medsger TA Jr, et al. Scleroderma (systemic sclerosis): classification, subsets andpathogenesis. J Rheumatol 1988; 15: 202-5. PMID: 3361530.

[3]. Furst DE, Clements PJ, Steen VD, Medsger TA Jr, Masi AT,D'Angelo WA, et al. The modified Rodnan skin score is an accurate reflection of skin biopsy thickness in systemic sclerosis. J Rheumatol 1998; 25:84-8. PMID: 9458208.

[4]. Al-Dhaher FF, Pope JE, Ouimet JM. Determinants of morbidity and mortality of systemic sclerosis in Canada. Semin Arthritis Rheum 2010;39:269_ 77. PMID: 18706680.

[5]. Khanna D, Merkel PA. Outcome measures in systemic sclerosis: an update on instruments and current research. Curr Rheumatol Rep 2007;9:151-7. PMID: 17502046.

[6]. Clements PJ, Hurwitz EL, Wong WK, Seibold JR, Mayes M, White B, et al. Skin thickness score as a predictor and correlate of outcome in systemic sclerosis: high-dose versus low-dose penicillamine trial. Arthritis Rheum 2000; 43:2445-54. PMID: 11083267.

[7]. Steen VD, Medsger TA Jr. Severe organ involvement in systemic sclerosis with diffuse scleroderma. Arthritis Rheum 2000; 43:2437-44. PMID: 
11083266.

[8]. Sawicka k, michalska-jakubus $\mathrm{m}$,kowal $\mathrm{m}$, potembska E, krasowska D. Resistin: a possible biomarker of organ involvement in systemic sclerosis patients?. clin exp rheumatol 2017; 35 (suppl. 106):s144-50. PMID: 28980898.

[9]. Barsotti S, Stagnaro C, Dascanio A, Della Rossa A. One Year In Review 2016: Systemic Sclerosis. Clin Exp Rheumatol. 2016; 34 (Suppl. 100): S313. PMID: 27463613

[10]. Shand L, Lunt M, Nihtyanova S, Hoseini M, Silman A, Black CM, et al. Relationship Between Change in Skin Score and Disease Outcome in Diffuse Cutaneous Systemic Sclerosis. Arthritis Rheum Vol. 2007. 56, 24222431. PMID: 17599771.

[11]. DeMarco PJ, Weisman MH, Seibold JR, Furst DE, Wong WK,Hurwitz EL, et al. Predictors and outcomes of scleroderma renal crisis: the High-Dose Versus Low-Dose D-Penicillamine in Early Diffuse Systemic Sclerosis Trial. Arthritis Rheum. 2002; 46:2983-9. PMID: 12428241.

[12]. Mukherjee m, mercurio v, tedford rj, Shah AA, Hsu S, Mullin CJ, et al. Right ventricular longitudinal strain is diminished in systemic sclerosis compared with idiopathic pulmonary arterial hypertension. 2017 Nov 22; 50(5): 1701436. PMID: 29167303.
[13]. Giordano M, Valentini G, Migliaresi S, Picillo U, Vatti M. Different antibody patterns and different prognoses in scleroderma patients with various extent of skin sclerosis. J Rheum. 1986 Oct; 13(5):911-6. PMID: 3546686.

[14]. Ioannidis JP, Vlachoy iannopoulos PG, Haidich AB, Medsger TAJr, Lucas $\mathrm{M}$, Michet CJ, et al. Mortality in systemic sclerosis: an international metaanalysis of individual patient data. Am J Med. 2005; 118: 2-10. PMID: 15639201.

[15]. Anton JM, Castro P, Espinosa G, Marcos M, Gandia M, Merchan R, et al. Mortality and long term survival prognostic factors of patients with systemic autoimmune diseases admitted to an intensive care unit: a retrospective study. Clin Exp Rheumatol. 2012; 30: 338-44. PMID: 22338619.

[16]. Domsic RT, Rodriguez-Reyna T, Lucas M, FertigN, Medsger TA Jr. Skin thickness progression rate: a predictor of mortality and early internal organ involvement in diffuse scleroderma. Ann Rheum Dis. 2011; 70: 104-9. PMID: 20679474.

[17]. Rubio-RivasM, Royo C, Simeon CP, Corbella X, Fonollosa V. Mortality and survival in systemic sclerosis: systematic review and meta-analysis. Semin Arthritis Rheum. 2014 Oct; 44(2): 208-19. PMID: 24931517. 